\title{
An equation of state for the gas phase of methanol
}

\author{
R.J.B. Craven, K.M. de Reuck and W.A. Wakeham \\ IUPAC Thermodynamic Tables Project Centre, \\ Department of Chemical Engineering and Chemical Technology, \\ London SW7 2BY, England
}

\begin{abstract}
A critical review of the very extensive literature on methanol reveals a lack of accurate $\mathrm{P} \rho \mathrm{T}$ data in the gas phase. In order to utilise the available and accurate measurements of enthalpy, isobaric heat capacity and speed of sound, an equation of state has been developed for the gas phase in terms of a reduced Gibbs energy function. Comparisons are given of the experimental data with the equation of state and the problems caused by decomposition are discussed. The successful representation of the effects of association on the isobaric heat capacity is illustrated.
\end{abstract}

\section{INTRODUCTION}

There is a very extensive literature on methanol, but because of the experimental problems, which are discussed in the next section, a thorough critical review revealed only a limited amount of accurate data. An early attempt to produce an equation of state for the whole surface was made by Zubarev, Prusakov and Sergeeva (ref. 1) who published tables of the thermodynamic properties over the range 178 to $573 \mathrm{~K}$, for pressures up to 50MPa. More recently, Goodwin (ref. 2) at the National Bureau of Standards, published tables based on his equation of state. These equations rely heavily on $\mathrm{P} \rho \mathrm{T}$ data, but for methanol the reliable $\mathrm{P} \rho \mathrm{T}$ data in the gas phase cover a very small range and it is therefore necessary to use other properties, such as enthalpy and isobaric heat capacity, which are less sensitive to the effects of adsorption and decomposition. However these properties cannot be used directly to fit the usual Helmholtz energy function since both types of data are measured as a function of pressure and temperature; also the isobaric heat capacities are non-linear in terms of the coefficients. The gas phase data were therefore fitted to a Gibbs energy function, and this will later be used to calculate input data for fitting a Helmholtz energy equation for the whole surface.

\section{EXPERIMENTAL PROBLEMS}

There are three major problems encountered when making experimental thermodynamic measurements on methanol, and since they are a frequent source of error, they are discussed separately.

\section{Purity}

The most common impurity is water, which is very difficult to remove (see recommendations in ref. 3 ). Since methanol is very hygroscopic any quoted water impurity content is likely to be unreliable unless care has been taken to exclude moist air from the stored sample. The presence of water reduces the vapour pressure, increases the density, the enthalpy of evaporation and the heat capacity.

\section{Adsorption}

Gaseous methanol adsorbs readily onto many surfaces and results in an increase in the apparent density. The size of the error depends on both the experimental method and the nature of the surface. If adsorption isotherms are measured separately corrections can be made for it, or it can be partly compensated for when using gas density balance methods. Fischer et al. (ref. 4) found that adsorption effects at temperatures below $329 \mathrm{~K}$ were greater than the experimental errors from other sources if the relative pressure $P / P_{\sigma}$ was greater than 0.37 , where $P_{\sigma}$ is the saturation pressure. Therefore at lower temperatures measurements of the saturated vapour density or densities near to saturation are likely to be unreliable. In the presence of adsorption, measured second virial coefficients are too negative. For most of the earlier density measurements inadequate care was taken either to eliminate or correct for adsorption. 


\section{Decomposition}

As with adsorption, decomposition is dependent on the nature of the surface as well as the temperature and pressure, but also on the residence time of the methanol under these experimental conditions. In the gas phase at low pressures, below about $0.16 \mathrm{MPa}$, significant decomposition is not observed until a temperature of $650 \mathrm{~K}$ is reached (see ref. 4). At higher pressures, about $3.4 \mathrm{MPa}$, chemical reaction or decomposition has been observed in the gas for temperatures as low as $473 \mathrm{~K}$ (see refs. 5 and 6 ), and also at this temperature at pressures of $800 \mathrm{MPa}$ in the liquid (see ref. 7 ). Therefore measurements at any temperature greater than $473 \mathrm{~K}$ for pressures above $3.4 \mathrm{MPa}$ may be affected by decomposition. Amongst the gaseous products of decomposition, which have been observed, are methane, hydrogen, carbon dioxide and carbon monoxide and in the liquid, acetone, dimethyl ether, methyl formate, formaldehyde, acetals and hemiacetals. Bruno and Straty (ref. 6) tested the catalytic behaviour of $316 \mathrm{~L}$ stainless steel, which was the material used by Straty et al. (ref. 8) for their PVT vessel, and they reported that "serious decomposition/reaction problems are seen to begin at $[473 \mathrm{~K}]$ and become extremely severe at $[523 \mathrm{~K}]$." Ta'ani (ref. 7) was able to suppress the decomposition for temperatures up to $523 \mathrm{~K}$ by fitting a monel (alloy of copper and nickel) metal tube into his vessel. An attempt has been made by Straty et al. (ref. 8) to measure the rate of change of pressure due to decomposition with time and to use this to correct their P $\rho \mathrm{T}$ data. Yerlett and Wormald (ref. 9) analysed some of their samples at the end of the run in order to measure the amount of impurities present, and to calculate the probable error caused by them.

\section{ASSOCIATION}

The presence of hydrogen bonds in methanol vapour results in the formation of polymeric clusters, which cause a rapid increase in the heat capacity especially near saturation. This is shown in the measurements of isobaric heat capacities by De Vries and Collins (ref. 10), Weltner and Pitzer (ref. 11), Sinke and De Vries (ref. 12), Counsell and Lee (ref. 13) and Strömsöe et al. (ref. 14) (see Fig. 1). The effect of association on the measured densities or second virial coefficients is similar to that of adsorption, that is, the density is higher and the second virial coefficients are more negative than those expected for an unassociated gas.

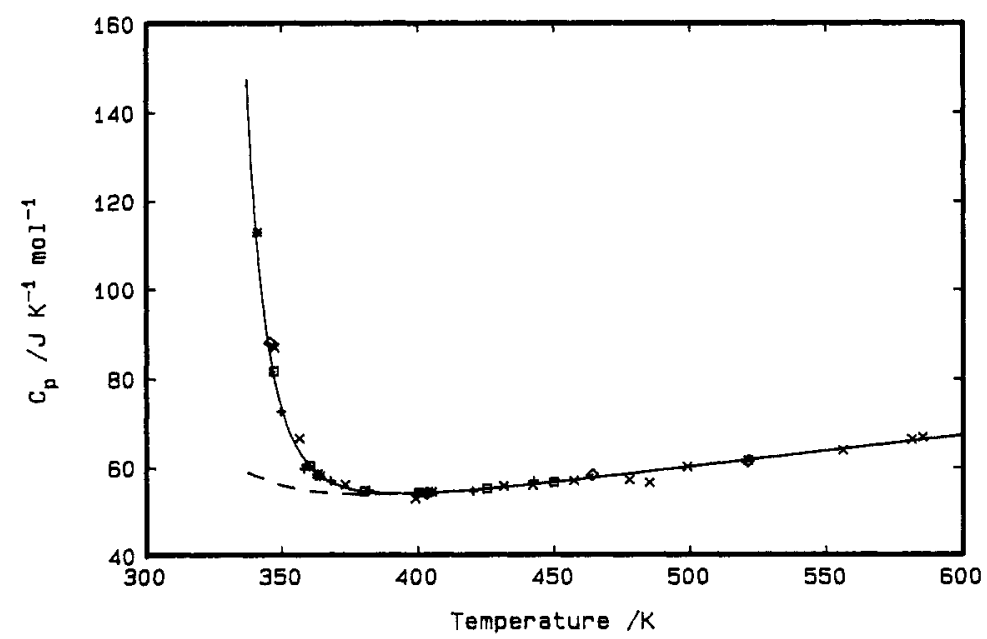

Fig. 1 Comparisons of the isobaric heat capacities with equations (2) and (13).

a: Counsell and Lee (ref. 13); $\diamond$ : Weltner and Pitzer (ref. 11); +: De Vries and Collins (ref. 10); *: Sinke and De Vries (ref. 12); $\times$ : Strömsöe et al. (ref.14); —: equations (2) and (13);

--- Goodwin (ref. 2) equation of state.

\section{DEVELOPMENT OF THE GIBBS EQUATION OF STATE}

The equation of state is expressed in the form of a reduced Gibbs energy written in an analogous way to the usual Helmholtz energy function as

$$
\mathrm{G}(\pi, \tau) / \mathrm{RT}=\gamma^{\mathrm{id}}(\tau)+\ln \left(\pi / \pi_{\mathrm{a}}\right)+\gamma(\pi, \tau)
$$

where $\pi=\mathrm{P} / \mathrm{P}^{*}, \tau=\mathrm{T}^{*} / \mathrm{T}$ and $\mathrm{P}^{*}$ and $\mathrm{T}^{*}$ are reducing parameters. The entropy and enthalpy are taken to be zero at an arbitrary reference point $\left(\pi_{a}, \tau_{a}\right)$ in the ideal gas. The pressure-dependent part of the ideal gas is represented by $\ln \left(\pi / \pi_{\mathrm{a}}\right)$ and the temperature-dependent part by $\gamma^{\text {id }}(\tau)$ which can be calculated from the ideal gas isobaric heat capacity, $\mathrm{C}_{\mathrm{p}}^{\mathrm{id}}$, by the relationship

$$
\gamma^{\mathrm{id}}(\tau)=-\iint \mathrm{C}_{\mathrm{p}}^{\mathrm{id}} /\left(\mathrm{R} \tau^{2}\right) \mathrm{d} \tau \mathrm{d} \tau
$$


The equation for $\mathrm{C}_{\mathrm{p}}^{\mathrm{id}}$ used here is from Craven and de Reuck (ref. 15).

The function $\gamma(\pi, \tau)$ represents the real part of the reduced Gibbs energy for the gas, and the general functional form chosen for the "bank" of 111 terms is given by

$$
\gamma \operatorname{gen}(\pi, \tau)=\sum_{\mathrm{i}=1} \sum_{j=1} \mathrm{n}_{\mathrm{ij}} \pi^{\mathrm{r}_{\mathrm{i}}} \tau^{\mathrm{s}_{\mathrm{j}}}+\sum_{\mathrm{i}=1} \mathrm{n}_{\mathrm{i}} \pi^{\mathrm{r}_{\mathrm{i}}} \exp \left(\mathrm{q}_{\mathrm{i}} \tau\right)
$$

The linear coefficients $n_{i j}$ and $n_{i}$ were determined using SEEQ (ref. 16), which is a multi-property least-squares method where the statistically-significant terms are selected from the original bank of terms: the method was first developed by Wagner (ref. 17) for fitting vapour pressure curves.

The exponential temperature terms in eq. (3) were included to account for the association of the molecules in the gas. The form of the terms was proposed by Weltner and Pitzer (ref. 11) from a model of polymerisation based on the arbitrary assumption that the heat of polymerisation is constant and $\Delta \mathrm{C}_{p}$ of polymerisation is zero. The terms represent dimers and higher polymers up to clusters of seven molecules, and the numerical constants $q_{i}$ used here were based on those from Counsell and Lee (ref. 13).

In terms of eq. (3) the compression factor $\mathrm{z}$ is given by

$$
z=1+\pi(\partial \gamma / \partial \pi) \tau
$$

The weighted sum of squares to be minimised for $\mathrm{P} \rho \mathrm{T}$ data is given by

$$
\left.\mathrm{S}_{1}=\sum_{\mathrm{m}=1}^{\mathrm{M} 1}\left[\frac{\mathrm{z}-1}{\pi}-\left[\frac{\partial \gamma}{\partial \pi}\right]\right]_{\tau}\right]_{\mathrm{m}}^{2} / \sigma_{\text {Res } 1, \mathrm{~m}}^{2}
$$

where $\mathrm{M} 1$ is the total number of $\mathrm{P} \rho \mathrm{T}$ data points and $\sigma_{\text {Res } 1}^{2}$ is the estimated variance for each data point calculated using the Gaussian error propagation formula.

In terms of eqs. (1) and (3) the enthalpy is given by

$$
\frac{\mathrm{H}(\pi, \tau)}{\mathrm{RT}}=\tau\left[(\partial \gamma / \partial \tau)_{\pi}+(\partial \gamma \mathrm{id} / \partial \tau)\right]
$$

so the weighted sum of squares to be minimised for these data is

$$
\mathrm{S}_{2}=\sum_{\mathrm{m}=1}^{\mathrm{H} 2}\left[\frac{\mathrm{H}(\pi, \tau)-\mathrm{H}\left(\pi_{\mathrm{s}}, \tau_{\mathrm{s}}\right)}{\mathrm{RT}}-\tau\left\{\left[\frac{\partial \gamma}{\partial \tau}\right]_{\pi}+\left[\frac{\partial \gamma^{\mathrm{id}}}{\partial \tau}\right]-\left[\frac{\partial \gamma}{\partial \tau}\right]_{\pi_{\mathrm{s}}}-\left[\frac{\partial \gamma^{\mathrm{id}}}{\partial \tau}\right]_{\tau_{\mathrm{s}}}\right\}\right]_{\mathrm{m}}^{2} / \sigma_{\mathrm{Res} 2, \mathrm{~m}}^{2}
$$

where the point $\left(\pi_{\mathrm{s}}, \tau_{\mathrm{s}}\right)$ is that of the saturated vapour at $298.15 \mathrm{~K}$. There are also some $\Delta \mathrm{H}$ measurements at constant temperature, where the weighted sums of squares is

$$
\mathrm{S}_{3}=\sum_{\mathrm{m}=1}^{\mathrm{K} 3}\left[\frac{\Delta \mathrm{H}}{\mathrm{RT}}-\tau\left\{\left[\frac{\partial \gamma_{1}}{\partial \tau}\right]_{\pi}-\left[\frac{\partial \gamma_{2}}{\partial \tau}\right]_{\pi}\right\}\right]_{\mathrm{m}}^{2} / \sigma_{\text {Res } 3, \mathrm{~m}}^{2}
$$

The weighted sums of squares to be minimised for isobaric heat capacities is

$$
\mathrm{S}_{4}=\sum_{\mathrm{m}=1}^{\mathrm{M}}\left[\frac{\mathrm{C}_{\mathrm{p}}}{\mathrm{R \tau ^{2 }}}+\left[\frac{\partial^{2} \gamma}{\partial \tau^{2}}\right]_{\pi}+\left[\frac{\partial^{2} \gamma^{\mathrm{id}}}{\partial \tau^{2}}\right]\right]_{\mathrm{m}}^{2} / \sigma_{\text {Res } 4, \mathrm{~m}}^{2}
$$

The speed of sound is non-linear in terms of the coefficients $n_{i j}$ and $n_{i}$, but if values for $C_{p} / C_{v}$ and the density are taken from a previous fit, then experimental speed of sound data can be used to include the slope $\left(\partial^{2} \gamma / \partial \pi^{2}\right)_{\tau}$ into the fit. The speed of sound can be defined as

$$
\mathrm{w}^{2}=\left(\mathrm{C}_{\mathrm{p}} / \mathrm{C}_{\mathrm{v}}\right)(\partial \mathrm{P} / \partial \rho)_{\mathrm{T}} / \mathrm{M}
$$

and using eq. (3)

$$
\left[\frac{\partial \mathrm{P}}{\partial \rho}\right]_{\tau}=\operatorname{RT}\left\{\frac{\left[1+\pi(\partial \gamma / \partial \pi)_{\tau}\right]^{2}}{1-\pi^{2}\left(\partial^{2} \gamma / \partial \pi^{2}\right)_{\tau}}\right\}
$$


So the weighted sum of squares to be minimised for these data is

$$
\mathrm{S}_{5}=\sum_{\mathrm{m}=1}^{\mathrm{M} 5}\left[1-\frac{\mathrm{P}^{2}\left(\mathrm{C}_{\mathrm{V}} / \mathrm{C}_{\mathrm{V}}\right)}{\mathrm{M} \rho^{2} \mathrm{RT}^{2}(\pi, \tau)}-\pi^{2}\left[\frac{\partial^{2} \gamma}{\partial \pi^{2}}\right]\right]_{\tau}^{2} / \sigma_{\mathrm{Res} 5, \mathrm{~m}}^{2}
$$

where $\mathrm{M}$ is the molar mass.

The total sum of squares which was minimised was $S_{1}+S_{2}+S_{3}+S_{4}+S_{5}$.

\section{DATA USED IN THE FIT OF THE GIBBS EQUATION}

The data used to determine the coefficients $n_{i j}$ and $n_{i}$ of eq. (3) are listed in Table 1. As discussed previously there are very few $\mathrm{P} \rho \mathrm{T}$ data sets which were considered to be of sufficient accuracy to use in the fitting procedure. The low pressure measurements by Fischer et al. (ref. 4) and by Bich et al. (ref. 18) were used with minor corrections by the authors (ref. 19); their lowest temperature values were omitted because the authors considered that adsorption was causing errors (ref. 19). The calculated saturated vapour densities from the triple point to $8.0 \mathrm{MPa}$ were included as $\mathrm{P} \rho \mathrm{T}$ data. These were calculated using the Clausius-Clapeyron relation together with auxiliary equations fitted to experimental vapour pressures, saturated liquid densities and enthalpies of evaporation. Since the enthalpies of evaporation had to be extrapolated, an iterative procedure was used until a physically realistic set of saturated vapour densities was obtained.

The gas phase specific enthalpy data of Yerlett and Wormald (ref. 9) were measured in a flow calorimeter; the data of Lydersen (ref. 20) were isothermal measurements of $\Delta \mathrm{H}$.

Table 1. Selected data used to determine the coefficients of equation (13)

\begin{tabular}{|c|c|c|c|c|}
\hline Source & Date & $\begin{array}{l}\text { Temperature } \\
\text { range/K}\end{array}$ & $\begin{array}{l}\text { Pressure } \\
\text { range/MPa }\end{array}$ & No. of points \\
\hline $\begin{array}{l}\mathrm{P} \rho \mathrm{T} \\
\text { Fischer et al (refs. } 4,19) \\
\text { Bich et al (refs. 18,19) } \\
\text { Straty et al (ref. } 8 \text { ) }\end{array}$ & $\begin{array}{l}1972 \\
1984 \\
1986\end{array}$ & $\begin{array}{l}329-634 \\
356-628 \\
498-573\end{array}$ & $\begin{array}{l}0.026-0.21 \\
0.057-0.19 \\
5 \cdot 3-8 \cdot 0\end{array}$ & $\begin{array}{l}42 \\
19 \\
38\end{array}$ \\
\hline \multicolumn{5}{|l|}{$\mathrm{P}_{\sigma} \rho \mathrm{g}_{\sigma} \mathrm{T}_{\sigma}$} \\
\hline Calculated & & $175-510$ & $1.7 \times 10^{-7}-8.0$ & 68 \\
\hline $\begin{array}{l}\text { Enthalpy } \\
\text { Yerlett and Wormald (ref. 9) } \\
\text { Lydersen (ref. 20) }\end{array}$ & $\begin{array}{l}1986 \\
1986\end{array}$ & $\begin{array}{l}373-573 \\
428-564\end{array}$ & $\begin{array}{l}0 \cdot 1-7 \cdot 6 \\
1 \cdot 5-7 \cdot 4\end{array}$ & $\begin{array}{l}55 \\
77\end{array}$ \\
\hline $\begin{array}{l}\text { De Vries and Collins (ref.10) } \\
\text { Weltner and Pitzer (ref. 11) } \\
\text { Sinke and De Vries (ref. 12) } \\
\text { Counsell and Lee (ref. 13) }\end{array}$ & $\begin{array}{l}1941 \\
1951 \\
1953 \\
1973\end{array}$ & $\begin{array}{l}350-420 \\
346-521 \\
341-405 \\
330-450\end{array}$ & $\begin{array}{c}0.1 \\
0.1 \\
0.1 \\
0.025-0 \cdot 1\end{array}$ & $\begin{array}{c}7 \\
3 \\
4 \\
26\end{array}$ \\
\hline Goodwin and Ewing (ref. 21) & 1986 & $280-320$ & $<0.022$ & 84 \\
\hline
\end{tabular}

\section{GIBBS ENERGY EQUATION OF STATE}

The complete Gibbs energy equation of state is given by eq. (1) where the equation for the reduced Gibbs energy of the real gas contains 16 terms and is given by

$$
\gamma(\pi, \tau)=\sum_{i=1}^{12} a_{i} \pi^{I_{i}} \tau^{s_{i}}+\sum_{i=13}^{16} a_{i} \pi^{I_{i}} \exp \left(q_{i} \tau\right)
$$

The coefficients $a_{i}$ and $q_{i}$ and exponents $r_{i}$ and $s_{i}$ are given in Table 2, together with the values for $P^{*}$ and $T^{*}$, the gas constant $R$ and molar mass $M$. The fitting procedure selected four of the special association terms, but whilst three of these have negative coefficients the fourth is positive and so they 
can only be considered as empirical parameters, and no conclusions can be drawn about the size of the molecular clusters.

Table 2. Numerical values of the coefficients $a_{i}$ and $q_{i}$ and the exponents $r_{i}$ and $s_{i}$ of equation (13)

\begin{tabular}{|c|c|c|c|c|}
\hline $\mathrm{i}$ & $a_{i}$ & $q_{i}$ & $I_{i}$ & $s_{i}$ \\
\hline $\begin{array}{l}1 \\
2 \\
3 \\
4 \\
5 \\
6 \\
7 \\
8 \\
9 \\
10 \\
11 \\
12 \\
13 \\
14 \\
15 \\
16\end{array}$ & $\begin{array}{c}-0.0888379366533 \\
0.464897841530 \\
-2 \cdot 91410841638 \\
2.38732312736 \\
-0.860093122904 \\
1.10560180672 \\
-0.284704391367 \\
-0.945290986597 \\
1.01821325673 \\
-0.307950196724 \\
0.856718115499 \\
-0.536621462787 \\
-0.00536368707259 \\
-0.21416713393810^{-11} \\
0.267248 \quad 55080710^{-17} \\
-0.725750174566 \quad 10^{-23}\end{array}$ & $\begin{array}{c}- \\
= \\
= \\
= \\
= \\
= \\
= \\
- \\
- \\
3 \cdot 9014665 \\
23 \cdot 213127 \\
34 \cdot 234553 \\
45 \cdot 255979\end{array}$ & $\begin{array}{l}1 \\
2 \\
3 \\
3 \\
3 \\
4 \\
5 \\
5 \\
4 \\
4 \\
6 \\
6 \\
1 \\
3 \\
4 \\
5\end{array}$ & $\begin{array}{c}4 \\
0 \\
0 \\
1 \\
7 \\
0 \\
0 \\
9 \\
14 \cdot 5 \\
19 \cdot 5 \\
14 \cdot 5 \\
19 \cdot 5 \\
- \\
- \\
- \\
-\end{array}$ \\
\hline
\end{tabular}

$\mathrm{P}^{*}=8.0845 \mathrm{MPa}, \mathrm{T}^{*}=512.574 \mathrm{~K}, \mathrm{R}=8.31434 \mathrm{~J} \mathrm{~K}^{-1} \mathrm{~mol}^{-1}, \mathrm{M}=0.03204216 \mathrm{~kg} \mathrm{~mol}^{-1}$

\section{COMPARISONS OF THE GIBBS EQUATION WITH DATA}

$\mathbf{P} \rho \mathbf{T}$

The low pressure $\mathrm{P} \rho \mathrm{T}$ are well represented by the Gibbs equation of state (13); the data of Fischer et al. (refs. 4,19 ) which were used in the fit agree to within $\pm 0.06 \%$ in density and those of Bich et al. (refs. $18,19)$ to within $\pm 0 \cdot 1 \%$. For higher pressures and temperatures a comparison along representative isochores of the Straty et al. (ref. 8) data which were used in the fit with values predicted by eq. (13) is shown in Fig. 2. Except for close to the saturation curve and in the critical region, eq. (13) represents the
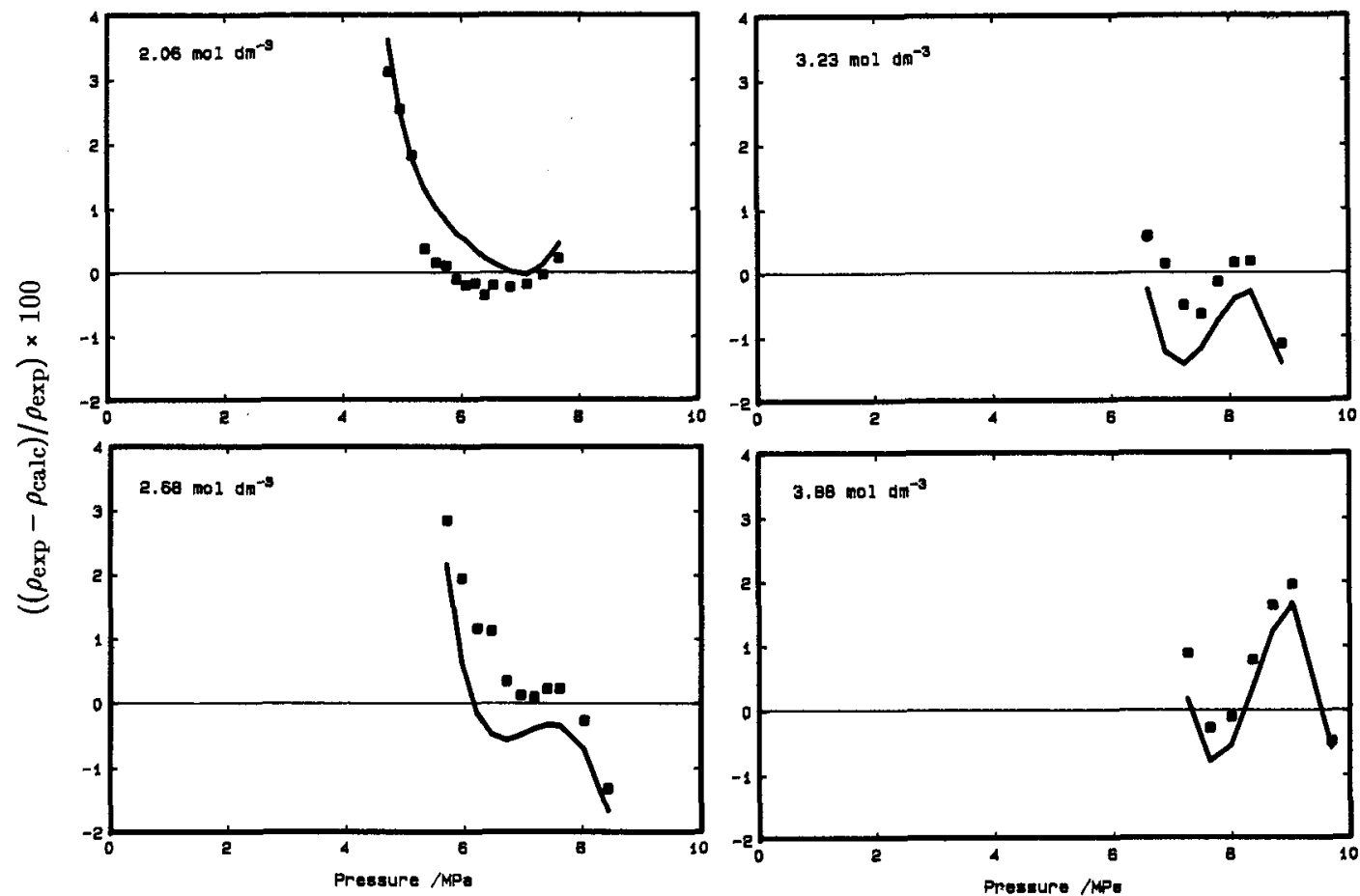

Fig. 2 Comparisons along isochores of the $\mathrm{P} \rho \mathrm{T}$ data with equation (13) and with the equation of state of Good win (ref. 2).

I.: Straty et al. (ref. 8); ——: Goodwin (ref. 2). 
data to within $\pm 1 \%$ in density, which is a considerably greater scatter than the quoted experimental accuracy of $\pm 0.2 \%$. As the saturation curve is approached the deviations increase rapidly; eq. (13) was fitted using saturated vapour densities calculated from saturation properties via the Clausius-Clapeyron relation and the Straty et al. data were omitted in this region. Values predicted by the Goodwin (ref. 2) equation of state are also given in Fig. 2; close to saturation these represent the Straty et al. data which were used to fit this equation. Elsewhere, the deviations of this equation and those of eq. (13) from the data are of a similar size.

The calculated saturated vapour densities agree with those predicted by the equation of state to within $\pm 0.1 \%$ for temperatures up to $460 \mathrm{~K}$, but at higher temperatures, where decomposition may occur, the deviations increase to several percent.

\section{Enthalpy}

Comparisons of values calculated using equations (2) and (13) with experimental data and with the equation of state of Goodwin (ref. 2) along representative isotherms are shown in Fig. 3. For pressures below about $4.0 \mathrm{MPa}$ the equation of state represents almost all the enthalpy measurements of Yerlett and Wormald (ref. 9) to within their experimental accuracy of $\pm 0.6 \%$. As the pressure increases so do the deviations which become mostly positive reaching a maximum of $2.3 \%$; this is in the region where they overlap with the P $\rho$ T data of Straty et al. (ref. 8). The Lydersen (ref. 20) $\Delta H$ values scatter evenly within $\pm 2 \cdot 0 \%$. Figure 3 shows that the Goodwin equation, which was produced by fitting P $\mathrm{P}$ data only, deviates in general more from the data than do values calculated from equation (13). This illustrates the necessity of using thermal data in addition to $\mathrm{P} \rho \mathrm{T}$ data when developing equations of state for complex fluids such as the alcohols.
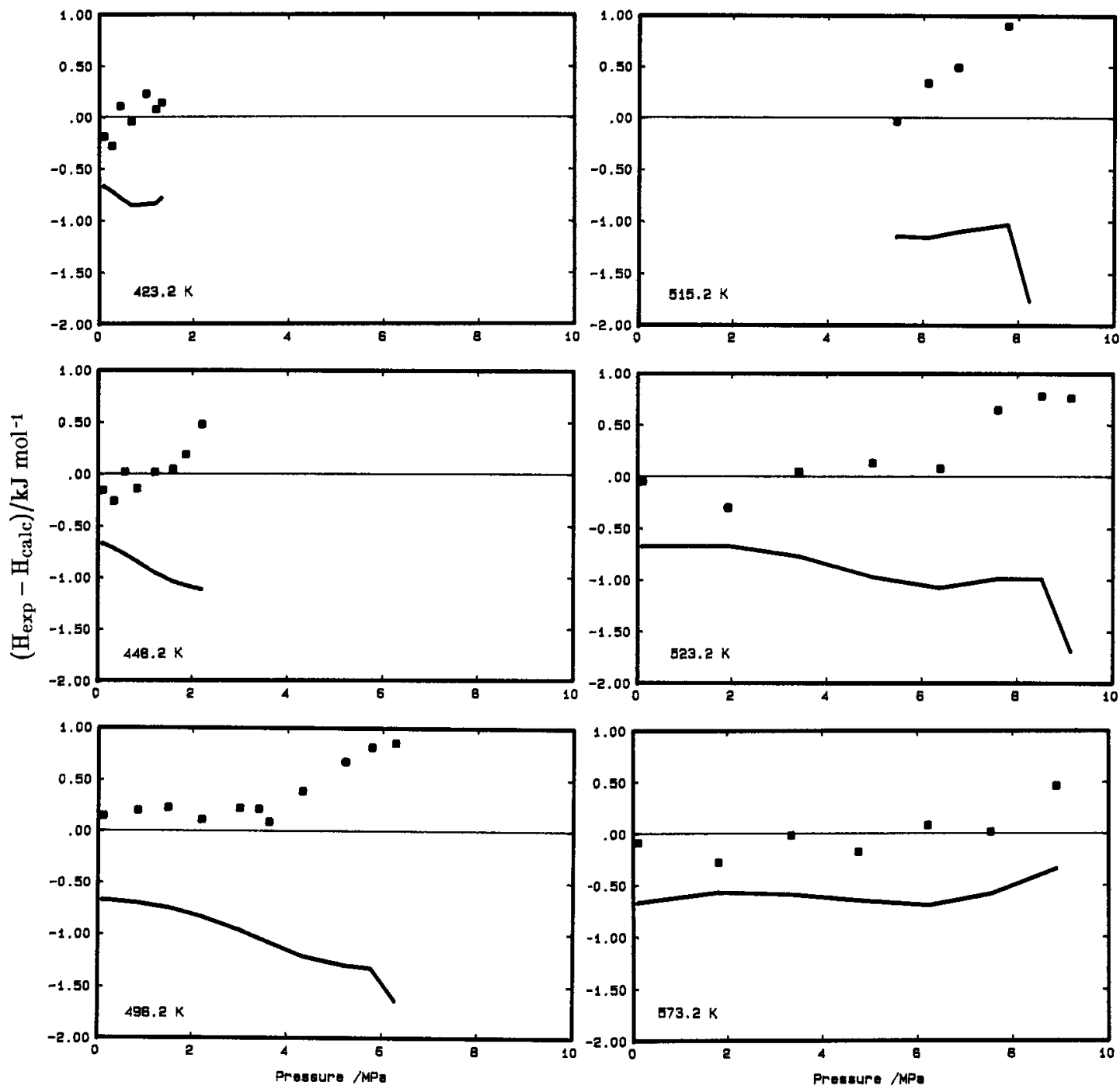

Fig. 3 Comparisons along isotherms of the enthalpy data with equations (2) and (13), and with the equation of state of Goodwin (ref. 2).

a: Yerlett and Wormald (ref. 9); —: Goodwin (ref. 2). 


\section{Isobaric heat capacity}

The $C_{p}$ data of Counsell and Lee (ref. 13), which were used, all agree with values calculated from the equation of state to within $\pm 0.5 \%$, with the largest deviations being near to the saturation curve; the experimental accuracy was given as $\pm 0.2 \%$. Figure 1 shows the behaviour of $\mathrm{C}_{\mathrm{p}}$ along the $0.1 \mathrm{MPa}$ isobar and the deviations of the various data sets from the curve calculated from the equation of state; the dashed curve represents values from the equation of state of Goodwin (ref. 2) at $0 \cdot 101325 \mathrm{MPa}$. The data of Strömsöe et al. (ref. 14) were not used in the fit. The exponential temperature terms in eq. (13) were essential to enable the steep rise in $\mathrm{C}_{\mathrm{p}}$ resulting from association of the molecules, to be reproduced.

\section{Speed of sound}

Deviations of speed of sound values predicted by the equation of state from the preliminary measurements of Goodwin and Ewing (ref. 21) are systematic in that, in general, along each isotherm the deviations increase negatively with increasing pressure, but the maximum deviation is only $-0 \cdot 13 \%$. The experimental precision is considerably higher than this but since these are the only data used in this region and they extend the temperature range $50 \mathrm{~K}$ below the P $\rho \mathrm{T}$ data used by Fischer et al. (ref. 4,19$)$, the agreement can be considered to be very good.

Speed of sound measurements by Akhmetyanov (ref. 22) were not used in the fit. Values in the saturated vapour are reproduced by the equation of state to within -0.5 to $+2.5 \%$ for temperatures up to $475 \mathrm{~K}$, but at higher temperatures the deviations increase to a maximum of nearly $-9.0 \%$. For pressures up to $3.4 \mathrm{MPa}$ the single-phase values are reproduced to within $\pm 2.0 \%$, but at higher pressures the deviations increase to a maximum of $+9.0 \%$. Again, the increased deviations occur for measurements above $473 \mathrm{~K}$ and $3.4 \mathrm{MPa}$, where decomposition is known to occur.

\section{Second virial coefficient}

Second virial coefficient data were not included in the fit of the equation of state and its predictions are systematically less negative than those given by Fischer et al. (refs. 4,19) and by Bich et al. (refs. 18,19) by about $15 \mathrm{~cm}^{3} \mathrm{~mol}^{-1}$, for temperatures down to about $350 \mathrm{~K}$. The deviations of other data sets are in general much larger than this. Below $350 \mathrm{~K}$ all deviations are negative, that is, the predicted values are less negative than the experimental data, which is to be expected if the measurements were affected by adsorption.

\section{SUMMARISING THE FIT TO THE GIBBS EQUATION OF STATE}

All the properties are well represented by the equation of state for pressures up to about $4 \cdot 0 \mathrm{MPa}$ where the saturation temperature is $\sim 473 \mathrm{~K}$; this being the point above which decomposition is known to occur. Above this point the deviations for all properties become systematic and larger than the experimental errors. This occurs for the enthalpy data of Yerlett and Wormald (ref. 9), the P $\rho$ T data of Straty et al. (ref. 8), the calculated saturated vapour densities, as well as for the Akhmetyanov (ref. 22) speed of sound data at saturation which were not used in the fit. This systematic behaviour suggests that there are inconsistencies between the overlapping sets of enthalpy and $\mathrm{P} \rho \mathrm{T}$ data. In the $\mathrm{P} \rho \mathrm{T}$ measurements the same sample was kept in the cell for between 17 and $35 \mathrm{~h}$ and an attempt was made to correct for thermal degradation by measuring the rate of change of pressure with time. The authors report that the maximum effect due to decomposition will be at "intermediate densities near the critical region at temperatures above [513 K]". They conclude that the net effect on the pressure is small but "the isochore curvatures could be expected to be altered somewhat, affecting thermodynamic calculations in this region". It is therefore not surprising that there are systematic differences from the equation of state in the region where the P $\rho \mathrm{T}$ data of Straty et al. overlap with the enthalpy measurements of Yerlett and Wormald. For the enthalpy measurements the longest time of residence in the hot zone of the calorimeter was estimated to be $325 \mathrm{~s}$ and an analysis after the run at $573.2 \mathrm{~K}$ and $8.9 \mathrm{MPa}$ found impurities of acetone $(0.29$ mole percent), methyl formate $(0.18$ mole percent) and methyl acetate $(0.02$ mole percent). Yerlett and Wormald estimated the effect on their measurements of assuming that the impurities were acetone and methyl formate in the mole ration of $3 / 2$. The maximum error due to decomposition was for their run at $573.2 \mathrm{~K}$ and $13.64 \mathrm{MPa}$ where the error in the enthalpy increment was estimated to be $-0.6 \%$ or $-256 \mathrm{~J} \mathrm{~mol}^{-1}$. The effect of these impurities was to increase the enthalpy difference. They did not correct for this error, and in general the values calculated from eq. (13) are smaller than the measured data at the higher temperatures and pressures. Below $498 \cdot 2 \mathrm{~K}$ decomposition was found to be negligible.

\section{CONCLUSIONS}

For temperatures from $280 \mathrm{~K}$ to $630 \mathrm{~K}$ for pressures up to $4.0 \mathrm{MPa}$ all the selected data, except for the speed of sound measurements, are represented by the Gibbs equation of state (13), to within their experimental accuracy. At a pressure of $4.0 \mathrm{Ma}$ the saturation temperature is approximately $473 \mathrm{~K}$, and at pressures and temperatures greater than this the deviations from the equation of state increase progressively; this is almost certainly a result of decomposition occurring. It is probable that the enthalpy data is less affected by decomposition than the $\mathrm{P} \rho \mathrm{T}$ data because the time of residence in the hot part of the flow calorimeter is orders of magnitude less than the time the P $\rho T$ sample was maintained at high 
temperatures and pressures. The fact that decomposition is partly dependent on the material of the vessel means that, in this region of higher temperatures and pressures, systematic differences between different experimenters are inevitable.

Data with random errors of varying sizes can easily be included in a fit by adjusting the weights applied to each point, but systematic errors have serious consequences for derived properties and this is well illustrated by the deviations shown in Fig. 3.

The final aim of this project is to prepare a Helmholtz energy equation for the whole surface, using the Gibbs equation of state to calculate input data for the gas phase. However, the problem of decomposition may result in restricting the range of temperature and pressure for which such an equation will be valid. The other problems of purity, adsorption and association can be overcome.

\section{Acknowledgements}

The authors wish to thank Professor A.L. Lydersen for sending them his unpublished enthalpy data, Dr. M.B. Ewing for letting them have his preliminary results of the speed of sound in the gas phase, and Dr. C.J. Wormald for sending them his enthalpy data before publication. They also wish to thank Dr. J. Millat for sending the revised data on $\mathrm{P} \rho \mathrm{T}$ measurements in the gas phase by Professor G. Opel and his colleagues at Wilhelm-Pieck University, Rostock.

This work was supported by the United Kingdom Department of Trade and Industry.

\section{REFERENCES}

1. V.N. Zubarev, P.G. Prusakov and L.V. Sergeeva, Thermophysical Properties of Methyl Alcohol. GSSD, Izdatyel, Stvo Standartov, Moscow (1973).

2. R.D. Goodwin, J. Phys. Chem. Ref. Data, 16, 799-892 (1987)

3. Y. Marcus and S. Glikberg, Pure \& Appl. Chem., 57, 855-864 (1985).

4. S. Fischer, H. Köhler and G. Opel, WZ Rostock 21, M2, 181-189 (1972).

5. A.P. Kudchadker, PhD Thesis, Texas A \& M University (1968).

6. T.J. Bruno and G.C. Straty, J. Res. Natl. Bur. Stand., 91, 135-138 (1986).

7. R. Ta'ani, Doctoral Dissertation, Karlsruhe University (1976).

8. G.C. Straty, A.M.F. Palavra and T.J. Bruno, Int. J. Thermophys., 7, 1077-1089 (1986).

9. T.K. Yerlett and C.J. Wormald, J. Chem. Thermodyn., 18, 719-726 (1986).

10. T. De Vries and B.T. Collins, J. Am. Chem. Soc. 63 , 1343-1346 (1941).

11. W. Weltner and K.S. Pitzer, J. Am. Chem. Soc. 73, 2606-2610 (1951).

12. G.C. Sinke and T. De Vries, J. Am. Chem. Soc., 75, 1815-1818 (1953).

13. J.F. Counsell and D.A. Lee, $\underline{J}$. Chem. Thermodyn, $\underline{5}, 583-589$ (1973).

14. E. Strömsöe, H.G. Rönne and A.L. Lydersen, J. Chem. Eng. Data, 15, 286-290 (1970).

15. R.J.B. Craven and K.M. de Reuck, Int. J. Thermophys., $\underline{7}, 541-552$ (1986).

16. K.M. de Reuck and B. Armstrong, Cryogenics, 19, 505-512 (1979).

17. W. Wagner, Forschr.-Ber., VDI-Z 3 , No. 39 (1974).

18. E. Bich, R. Pietsch and G. Opel, Zeit. Phys. Chem. (Leipzig), 265, 396-400 (1984).

19. J. Millat (private communication of revised data prepared by Prof. G. Opel and his co-authors at Wilhelm-Pieck University, Rostock).

20. A.L. Lydersen (private communication).

21. A.R.H. Goodwin and M.B. Ewing (private communication).

22. K.G. Akhmetyanov, M.G. Shirkevich and I.B. Rozhdestvenskii, Prim. Ul'traakust. Issle. Veshtch.-M. MOPI, 18(4), 127-135 (1957) 